\title{
Synergistic Effect of Alloying Atoms on Intrinsic Stacking-Fault Energy in Austenitic Steels
}

\author{
Ling-Hong Liu ${ }^{1,2} \cdot$ Tou-Wen Fan ${ }^{1} \cdot$ Cui-Lan $\mathrm{Wu}^{1,3} \cdot$ Pan Xie $^{1} \cdot$ Ding-Wang Yuan ${ }^{1} \cdot$ Jiang-Hua Chen ${ }^{1}$
}

Received: 31 August 2016/Revised: 3 November 2016/Published online: 8 December 2016

(C) The Chinese Society for Metals and Springer-Verlag Berlin Heidelberg 2016

\begin{abstract}
Intrinsic stacking-fault energy is a critical parameter influencing the various mechanical performances of austenitic steels with high Mn concentrations. However, quantitative calculations of the stacking-fault energy (SFE) of the face-centered cubic (fcc) Fe, including the changes in concentrations and geometrical distribution of alloying atoms, cannot be obtained by using previous computation models. On the basis of the interaction energy model, we evaluated the effects of a single alloying atom (i.e., $\mathrm{Mn}, \mathrm{Al}, \mathrm{Si}, \mathrm{C}$ and $\mathrm{N}$ ), as well as its aggregates, including the $\mathrm{Mn}-X$ dimer and $\mathrm{Mn}_{2}-X$ trimer $(X=\mathrm{Al}, \mathrm{Si}, \mathrm{C}$ and $\mathrm{N})$ on the SFE of the fcc Fe via first-principle calculations. Given low concentrations $(<10 \mathrm{wt} \%)$ of alloying atoms, dimers and trimers, theoretical calculations reveal the following: (1) Alloying atom Mn causes a decrease in the SFE, whereas $\mathrm{Al}, \mathrm{Si}, \mathrm{C}$ and $\mathrm{N}$ significantly increase the SFE; (2) combination with other alloying atoms to form the $\mathrm{Mn}-X$ dimer $(X=\mathrm{Al}, \mathrm{Si}, \mathrm{C}$ and $\mathrm{N}$ ) exerts an effect on SFE that, to a certain extent, is close to that of the corresponding single $X$ atom; (3) the interaction between $\mathrm{Mn}_{2}-X$ and the stacking fault is stronger than that of the corresponding single $X$ atom, inducing a significant increase in the SFE of fcc Fe. The theoretical results we obtained demonstrate that the increase in SFE in high-Mn steel originates from the synergistic effect of Mn and other trace alloy atoms.
\end{abstract}

KEY WORDS: Stacking-fault energy; Synergism; First-principle calculation; Austenitic steel; Alloying effect

\section{Introduction}

Owing to superior mechanical characteristics, austenitic steels with high Mn concentrations can be potentially used as next-generation high-strength steels for industrial

Available online at http://link.springer.com/journal/40195

Ding-Wang Yuan

dwyuan@hnu.edu.cn

1 Center for High-Resolution Electron Microscopy, College of Materials Science and Engineering, Hunan University, Changsha 410082, China

2 College of Science, Central South University of Forestry and Technology, Changsha 410004, China

3 Hunan Province Key Laboratory for Spray Deposition Technology and Application, Hunan University, Changsha 410082, China applications [1]. The active deformation mechanism in austenitic steels is directly related to the stacking-fault energy (SFE) of the Fe matrix [2,3]. Experimental and theoretical studies indicate that substitutional and interstitial solutes inevitably influence the SFE of a matrix [4-9]; the effect mainly depends on solute concentration, temperature, grain size, as well as electronic and chemical interactions [10-12]. Experimentally, the determination of SFE mainly concerned with the measurements of the partial dislocation separation in the matrix, which strongly focuses on sample preparation, microstructure and chemical composition, among others [13, 14]. Theoretically, existing databases and established empirical relationships between SFE and chemical compositions are required for widely used semiempirical thermodynamic approaches $[15,16]$. Neither can provide an accurately quantitative dependence between the SFE as well as the composition and concentration of the alloying atoms. Thus, first- 
principle methods have been employed to determine the SFE in steels, such as Fe-N [17], Fe-Mn [8, 17, 18], Fe-C $[6,8,19]$ and $\mathrm{Fe}-\mathrm{Al}[8]$. Most of these calculations only provide the results at zero Kelvin, without considering spin polarization. Consequently, the calculated and measured values of SFE disagree. Regardless, these calculations can provide fundamental insights into the changes in SFE with respect to alloying atoms [6] and have been widely recognized. The effects of temperature and spin polarization on SFE have recently been considered in several studies $[20,21]$. However, efficient techniques require high computational complexity and costs. For simplicity, we focused on the variation in SFE caused by alloying atoms, which can reduce the effects of temperature and spin polarization to a certain extent.

High-Mn-containing steels with low SFE exhibit excellent mechanical properties because of their high work-hardening rates [22-26]. In addition to deformation twinning, dynamic strain aging (DSA) enhances the workhardening rate of $\mathrm{Fe}-\mathrm{Mn}-\mathrm{C}$ steels by contributing to flow stress. The resulting DSA is often regarded as the interaction of Mn-C couples with strain fields of dislocations [27-29]. Regardless, the DSA model in the study [30] suggests a single diffusion jump of the $\mathrm{C}$ atom in the $\mathrm{Mn}-\mathrm{C}$ point-defect complex around the stacking-fault (SF) region. Calculations by Medvedeva et al. [8] recently indicated that the formation of the $\mathrm{Mn}-\mathrm{C}$ dimer and the $\mathrm{D}_{3}$-type $\mathrm{Al}$ ordering near the $\mathrm{SF}$ plane restrains $\mathrm{SFE}$ growth. In addition to $\mathrm{Mn}-\mathrm{C}$, other dimers/trimers such as $\mathrm{Mn}-X$ or $\mathrm{Mn}_{2}-X(X=\mathrm{Al}, \mathrm{Si}, \mathrm{N}, \mathrm{C}$, etc. $)$ are rarely reported; however, they may exist in high-Mn steels and affect the work-hardening rate of low-SFE steels interacting with SF. Therefore, the SFE that governs the mechanical behavior of high-Mn steels should be closely related to the atomic distribution and concentration of alloying atoms $[22,31]$.

Atomic aggregates (e.g., dimer and trimer) of alloys significantly influence the performance of materials; yet, studies on this issue are rarely reported. The CALPHADtype (calculation of phase diagram) approach can potentially treat this system [32]; however, the calculations are relatively costly. The first-principle calculation provides an effective and widely used technique; however, the previous calculation models are mainly used to evaluate the effect of a single alloying atom $[17,19,33]$. Meanwhile, the variation in SFE remains unclear with respect to the concentration of the alloying atom in high-Mn steels. Regarding the addition of C, Schramm and Reed [13] showed a strong enhancement in SFE as a function of $\mathrm{C}$ concentration. Meanwhile, Brofman and Ansell [34] concluded that SFE is almost independent of $\mathrm{C}$ concentration. Petrov et al. [35] demonstrated that the SFE of the face-centered cubic (fcc) $\mathrm{Fe}$ initially decreases and then increases with increasing $\mathrm{C}$ concentration. Abbasi et al. [19] showed the significant increase in SFE as a function of $\mathrm{C}$ concentration. Some studies likewise demonstrated that the interstitial $\mathrm{N}$ atom decreased the SFE of fcc steel [36, 37]. Meanwhile, other studies found that the SFE increased with increasing $\mathrm{N}$ concentration [17, 38]. In addition, a nonmonotonic dependence of SFE on $\mathrm{N}$ concentration was predicted in several studies [16, 39]. Variations in the results may be attributed to flaws in different models. For example, the supercells are too small to avoid the interaction of alloying atoms, resulting in a less accurate description of concentration dependence. Thus, a method that systematically evaluates the effects of atomic clusters on SFE in multicomponent alloys needs to be developed.

In the present study, an effective model based on the interaction energy between alloying atoms and SF [40, 41] was employed to describe the effects of commonly used alloying atoms ( $\mathrm{Mn}, \mathrm{Al}, \mathrm{Si}, \mathrm{C}$ and $\mathrm{N}$ ), as well as $\mathrm{Mn}$ $X$ dimer and $\mathrm{Mn}_{2}-X$ trimer $(X=\mathrm{Al}, \mathrm{Si}, \mathrm{C}$ and $\mathrm{N})$ on the SFE of fcc Fe. The results we obtained indicate that under low concentrations $(<10 \mathrm{wt} \%)$, the alloying atom $\mathrm{Mn}$ decreases the SFE, whereas $\mathrm{Al}, \mathrm{Si}, \mathrm{C}$ and $\mathrm{N}$ significantly increase the SFE. The effect of $\mathrm{Mn}-X$ dimer $(X=\mathrm{Al}, \mathrm{Si}, \mathrm{C}$ and $\mathrm{N}$ ) on SFE is similar to that of the corresponding single $X$ atom. $\mathrm{Mn}_{2}-X$ can cause a significant increase in the SFE of fcc Fe.

\section{Computational Method}

All calculations were performed using the Vienna Ab initio Simulation Package (VASP) [42]. The interaction between ions and core electrons was described using the projector augmented wave method [43]. Generalized gradient approximation (GGA-PW91) [44] was employed for the exchange-correlation functional. The energy cutoff of $350 \mathrm{eV}$ was chosen to expand the plane-wave basis. The convergence criteria were forces acting on atoms smaller than $0.01 \mathrm{eV} / \AA$ and total energy less than $10^{-5} \mathrm{eV}$ per unit cell. After rigorous tests, the SFE value of pure fcc Fe with the nonmagnetic state was determined to be $-417 \mathrm{~mJ} / \mathrm{m}^{2}$ by using the well-known SFE equation $\gamma=\left(E_{\text {fault }}-E_{\text {per- }}\right.$ fect $) / A$, where $E_{\text {fault }}$ and $E_{\text {perfect }}$ are the total energies of the supercell with and without SF, and $A$ is the SF area. Our result is in agreement with the values obtained from previous ab initio calculations [8, 19, 33].

Intrinsic stacking fault (ISF) is one of the typical planar defects in the fcc structure, which refers to a fault in the layer stacking along the $<111>$ direction. For simplification, we construct an ISF by removing one (111) layer, i.e., changing from the perfect ...ABCABCABC...sequence to ...ABCIBCABC..., where $\mathrm{A}, \mathrm{B}$ and $\mathrm{C}$ are the closed-packed planes for (111), and the symbol I indicates 
the position of the fault. For convenience of description, we define the plane nearest to the fault as layer 1, the plane next to layer 1 is layer 2 , and the same for other planes, i.e., layers $3,4 \ldots$ and $n$ according to their distances to the $\mathrm{SF}$ plane. The increase in SFE caused by alloying atoms can be determined using the interaction energy model [40, 41],

$\Delta \gamma=\sum c_{n} E_{\text {int }-\mathrm{n}} / A$,

where $c_{n}$ is the concentration of alloying atom at the $n$th plane, $A$ is the area of the (111) plane, $E_{\mathrm{int}-n}$ is the interaction energy between SF and alloying atoms (single atom, dimer and trimer) when they are located in the $n$th plane $[40,41]$ :

$E_{\text {int-n }}=\left(E_{s-n-\mathrm{SF}}-E_{s-n}\right)-\left(E_{\mathrm{Fe}-\mathrm{SF}}-E_{\mathrm{Fe}}\right)$,

where $E_{\mathrm{s}-n-\mathrm{SF}}$ and $E_{\mathrm{s}-n}$ are the energies of Fe solid solution supercells with and without SF, respectively, and with one alloying atom/dimer/trimer located in the $n$th plane in both supercells. $E_{\mathrm{Fe}-\mathrm{SF}}$ and $E_{\mathrm{Fe}}$ are the energies of supercells of pure Fe with and without SF, respectively.

When calculating the SFE and $E_{\mathrm{int}-n}$ between different types of alloying atoms and SF, the large 14-(111)layer supercells were chosen to avoid the interaction between SFs. Specifically, a 126-atom supercell (with 14(111) layer and 9 atoms per layer) was used for pure fcc $\mathrm{Fe}$ and with one alloying atom distributed in the matrix. Larger 14-(111)-layer supercells with 16 and 36 atoms per layer were used for the SF structure including dimers and trimers, respectively. To determine the distribution of dimer and trimer in fcc Fe, 6-(111)-layer supercells with 16 and 36 atoms per layer were used, respectively. The $3 \times 3 \times 3$ cubic supercells with 108 atoms were chosen for calculating the binding energy $E_{\mathrm{b}}$ between alloying atoms $\mathrm{A}$ and $\mathrm{B}$ according to the following equation [8]:

$E_{\mathrm{b}}=\left[E_{(\mathrm{Fe}+\mathrm{A}+\mathrm{B})}+E_{(\mathrm{Fe})}\right]-\left[E_{(\mathrm{Fe}+\mathrm{A})}+E_{(\mathrm{Fe}+\mathrm{B})}\right]$

where $E_{(\mathrm{Fe}+\mathrm{A}+\mathrm{B})}$ is the energy of the supercell with both $\mathrm{A}$ and $\mathrm{B}, E_{(\mathrm{Fe}+\mathrm{A})}$ and $E_{(\mathrm{Fe}+\mathrm{B})}$ are the energies of the supercells with $\mathrm{A}$ or $\mathrm{B}$, respectively, and $E_{(\mathrm{Fe})}$ is the energy of pure Fe. The positive and negative binding energies correspond to the repulsive and attractive interactions between $\mathrm{A}$ and $\mathrm{B}$, respectively.

\section{Results and Discussion}

\subsection{Model Analysis and Influence of Single Alloying Atom on SFE}

To understand the effect of the atomic distribution of alloying atoms on SFE, substitutional solute atoms (Mn, $\mathrm{Al}$ and $\mathrm{Si}$ ) and octahedral-interstitial atoms $(\mathrm{C}$ and $\mathrm{N})$ were added to different layers (see Fig. 1a, b) in a supercell with
14-(111) layers and 9 atoms in each layer, which is used to mimic the dilute distribution of alloying atoms in the matrix. We first considered $E_{\mathrm{int}-n}$ between the SF and the additive atoms in different layers, as shown in Fig. 1a, b. The results are illustrated in Fig. 2.

The positive and negative interaction energies correspond to the repulsive and attractive interaction, respectively, between additive atoms and SFs. It is found that $E_{\text {int }-n}$ for all alloying atoms is in short range, i.e., they are quite large when the alloying atoms are added to layers 1 and 2 but are gradually reduced when alloy atoms are located 3 interlayer distances below the SF plane. $\mathrm{Al}, \mathrm{Si}, \mathrm{C}$ and $\mathrm{N}$ atoms exhibit marked repulsive interactions with $\mathrm{SF}$. Previous studies $[8,19]$ suggest that $\mathrm{C}$ remains homogeneously distributed in fcc $\mathrm{Fe}$ at room temperature even in the presence of an SF. For simplicity, we assume that other alloying atoms are homogeneously distributed in the matrix. Using $E_{\text {int }-n}$ and $c_{n}$, we obtained the increments in SFE caused by alloying atoms with arbitrary concentrations in accordance with Formula (1); the results are presented in Fig. 3a. The results we obtained are in good agreement with those found in other studies. A specific data comparison is shown in Fig. $3 \mathrm{~b}$ and Table 1.

The $\Delta \gamma$ values induced by 1 at.\% alloying atoms are listed in Table 1 for comparison with other reported results. Within the considered concentration range, $\mathrm{Mn}$ atoms slightly reduce the SFE; other alloying atoms, particularly the interstitial atoms $\mathrm{C}$ and $\mathrm{N}$, can markedly increase the SFE. This finding is consistent with the conclusions drawn by several studies $[5,8,17,19]$. Atoms such as $\mathrm{C}$ and $\mathrm{N}$ are often used to stabilize austenite at room temperature [6].

On the basis of ab initio investigations, Abbasi et al. [19] revealed that the $\mathrm{C}$-induced change in SFE depends linearly on the concentration of $\mathrm{C}$; the results are consistent with those obtained using the axial next-nearest neighbor Ising (ANNNI) approach and those determined in previous experimental studies [13], as shown in Fig. 3b. The concentration selected in our model was not restricted by the size of the supercell. More importantly, the results in this study contained no additional errors introduced by linearization as in previous studies [19], and the amount of computation was significantly reduced. Notably, the interaction energy model was highly concise and precise under the conditions of low concentration $(<10$ at. $\%)$ but was not applicable under the conditions of high concentration. The reason is that it was based on the interaction between one atom/dimer/trimer and SF, which is inconsistent with the actual situation when the alloying atoms/dimers/trimers exhibit considerably high concentrations. Many experimental and calculation results regarding $\mathrm{Fe}-\mathrm{Mn}$ alloys $[8,12,21]$ demonstrated that the SFE decreases with an increase in $\mathrm{Mn}$ concentration of $\mathrm{Mn}$ and then exhibits a linear relationship with them at concentrations ranging 
(a)

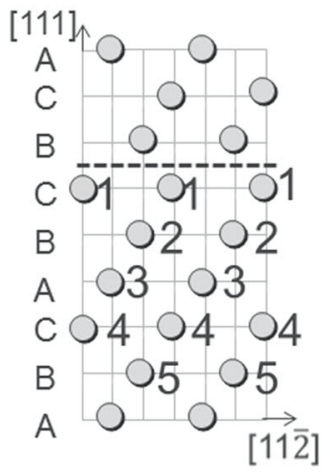

(d)

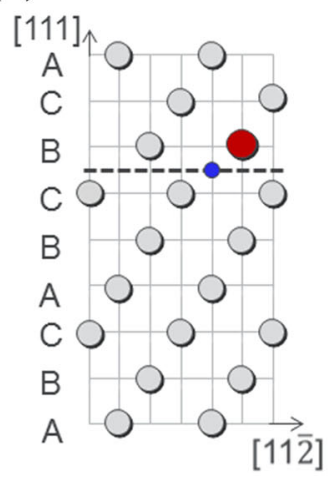

(b)

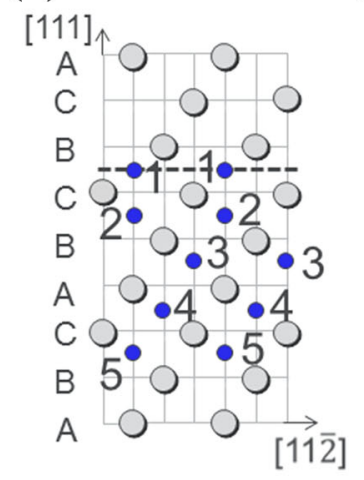

(e)

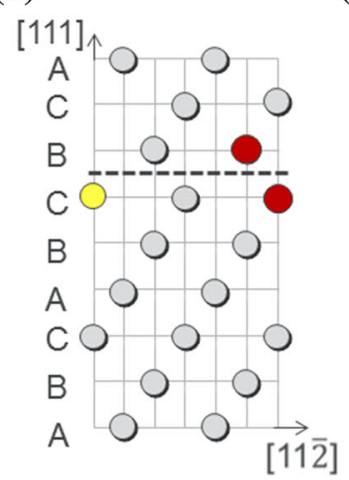

(c)

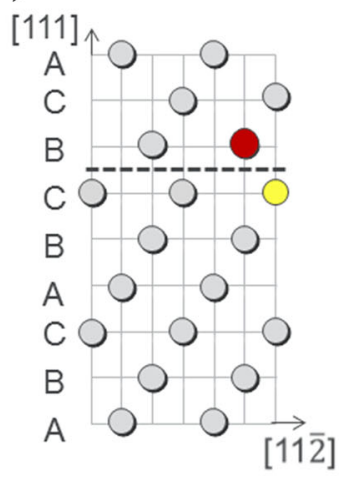

(f)

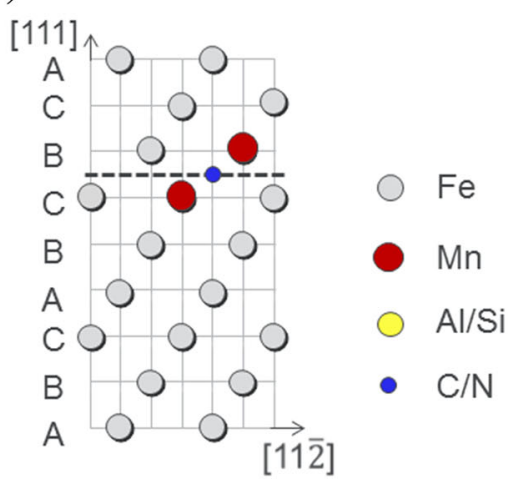

Fig. 1 Possible atomic configurations considered in our calculations. The positions of the substitutional atoms (i.e., Mn, Al, and Si) and interstitial atoms (e.g., $\mathrm{C}$ and $\mathrm{N}$ ) at octahedral sites in different layers are marked with numbers of 1-5 in a, b, respectively. The atomic distribution of dimers (i.e., $\mathrm{Mn}-\mathrm{Al}, \mathrm{Mn}-\mathrm{Si}, \mathrm{Mn}-\mathrm{C}$, and $\mathrm{Mn}-\mathrm{N}$ ) and trimers (i.e., $\mathrm{Mn}_{2}-\mathrm{Al}_{1} \mathrm{Mn}_{2}-\mathrm{Si}_{1} \mathrm{Mn} \mathbf{n}_{2}-\mathrm{C}$, and $\mathrm{Mn} \mathbf{}_{2}-\mathrm{N}$ ) is shown in $\mathbf{c}-\mathbf{f}$. The 8-(111)-layer supercells are demonstrated for simplicity. The dashed line shows the position of SF plane in supercell

from 0 to 10 at. $\%$, the SFE reaches the minimum when the Mn concentration is as high as 13 at.\%, and then it increases with increasing Mn concentration.

\subsection{Influence of Mn- $X$ Dimer on SFE}

This section discusses the effects of the $\mathrm{Mn}-X$ dimer on the SFE of fcc Fe. To determine the favorable configuration of $\mathrm{Mn}$ and $X$ atoms in the fcc Fe matrix, the total energies for the 6-(111)-layer supercells (16 atoms per layer) were compared with a $\mathrm{Mn}$ atom and another $X$ (Al, Si, Mn, C and $\mathrm{N}$ ) atom at different sites (Fig. 4a, sites 1-3 represent the nearest neighbor to the third-nearest neighbor positions of $\mathrm{Fe}$ and substitutional solutes $\mathrm{Al} / \mathrm{Si} / \mathrm{Mn}$. In Fig. 4b, sites 1-4 represent the nearest neighbor to the fourth-nearest neighbor positions of $\mathrm{Fe}$ and interstitials $\mathrm{C} / \mathrm{N}$ ). As shown in Table 2, Mn, Al and Si atoms prefer to occupy the nextnearest neighbor site of the $\mathrm{Mn}$ atom, whereas the interstitials $\mathrm{C}$ and $\mathrm{N}$ prefer to stay at the nearest neighbor site of the $\mathrm{Mn}$ atom. These results were consistent with those reported by Medvedeva et al. [8] and indicated the attractive interaction between $\mathrm{Mn}$ and $X$ atoms. Indeed, we determined that the binding energies $E_{\mathrm{b}}$ for both the nearest neighboring and the NNN Mn-Mn atoms are -9.2 and $-26.1 \mathrm{meV}$, respectively. These values suggest that $\mathrm{Mn}$ atoms can easily form the NNN atomic dimers in fcc Fe. The binding energies between the NNN $\mathrm{Mn}$ and $\mathrm{Al} / \mathrm{Si}$ atoms were -25.1 and $-14.3 \mathrm{meV}$, respectively, whereas the $\mathrm{Mn}-\mathrm{C}$ and $\mathrm{Mn}-\mathrm{N}$ binding energies were -26.1 and $-86.8 \mathrm{meV}$, respectively.

Owing to the short-range interaction between alloying atoms and $\mathrm{SF}$, the $\mathrm{Mn}-X$ dimers were located adjacent to SFs. The calculated interaction energies between SF and $\mathrm{Mn}-\mathrm{Al}, \mathrm{Mn}-\mathrm{Si}, \mathrm{Mn}-\mathrm{C}$ and $\mathrm{Mn}-\mathrm{N}$ added in layer 1 were 13.7, 15.4, 43.1 and $33.3 \mathrm{meV}$, respectively, i.e., larger than the algebraic sum of the interaction energy between SFs and the single Mn as well as the corresponding $X$ atom added in layer 1. The effect of Mn atom on the SFE was weakened by the combination of the Mn atom with other atoms. To compare the effects of the single alloying atom $X, \mathrm{Mn}-X$ dimer and $\mathrm{Mn}_{2}-X$ trimer (discussed in the next section) on SFE, we calculated the increment in SFE 


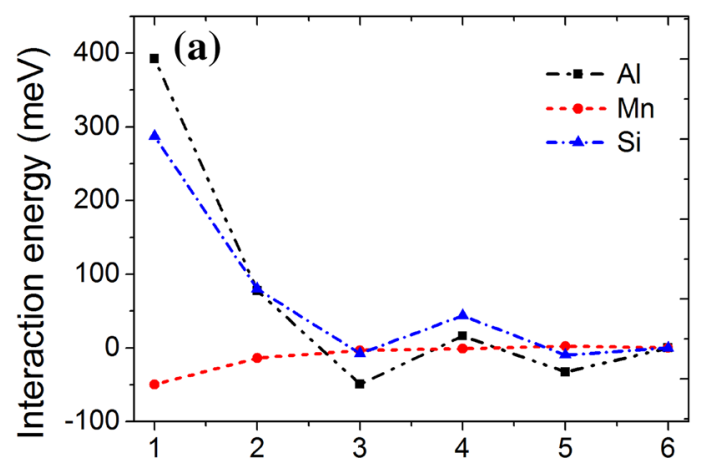

The number of layer in ISF structure

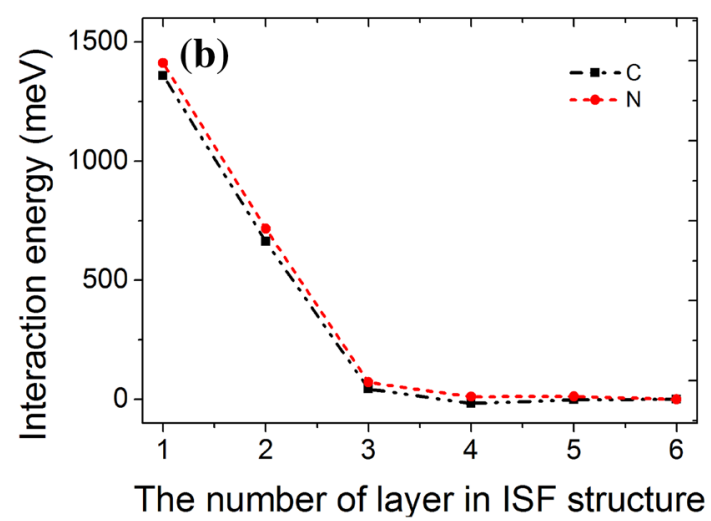

Fig. 2 Interaction energies $E_{\text {int }-n}$ between single alloying atom and $\mathrm{SF}$ as a function of distance from SF for substitutional atoms a, interstitial atoms $\mathbf{b}$

induced by 1 at.\% alloying atoms of the 3 kinds located nearest the SF, as shown in Fig. 5. This figure indicates that $\Delta \gamma$ induced by the $\mathrm{Mn}-\mathrm{C}$ dimer is slightly smaller than that of a single $\mathrm{C}$ atom, whereas $\Delta \gamma$ caused by other $\mathrm{Mn}-$ $X(X=\mathrm{Al}, \mathrm{Si}$ and $\mathrm{N})$ dimers and corresponding single $X$ atoms are almost equal; that is, when Mn combined with other atoms, a single Mn atom only slightly affects SFE.

\subsection{Influence of $\mathrm{Mn}_{2}-X$ Trimer on SFE}

As previously practiced, we first considered the configuration of $\mathrm{Mn}_{2}-X$ trimers. To avoid any interaction with other atoms, we chose a larger supercell with a 6-(111) layer and 36 atoms in each layer. In accordance with previous calculations, we placed $2 \mathrm{Mn}$ atoms at the NNN site and another $X(X=\mathrm{Al}, \mathrm{Si}, \mathrm{C}$ and $\mathrm{N})$ atom at different sites near the $2 \mathrm{Mn}$ atoms (Fig. 4c, sites 1-8, Fig. 4d, sites 1-7). Sites $1-8$ in Fig. $4 c$ and sites $1-7$ in Fig. $4 d$ were determined based on the distance between the $X$ atom and $2 \mathrm{Mn}$ atoms, respectively. The total energies for the supercells were compared. The results are listed in Table 3. For Al and $\mathrm{Si}$, position 6 (where the distances between the $X$ atom and $2 \mathrm{Mn}$ atoms are 3.450 and $4.879 \AA$, respectively)
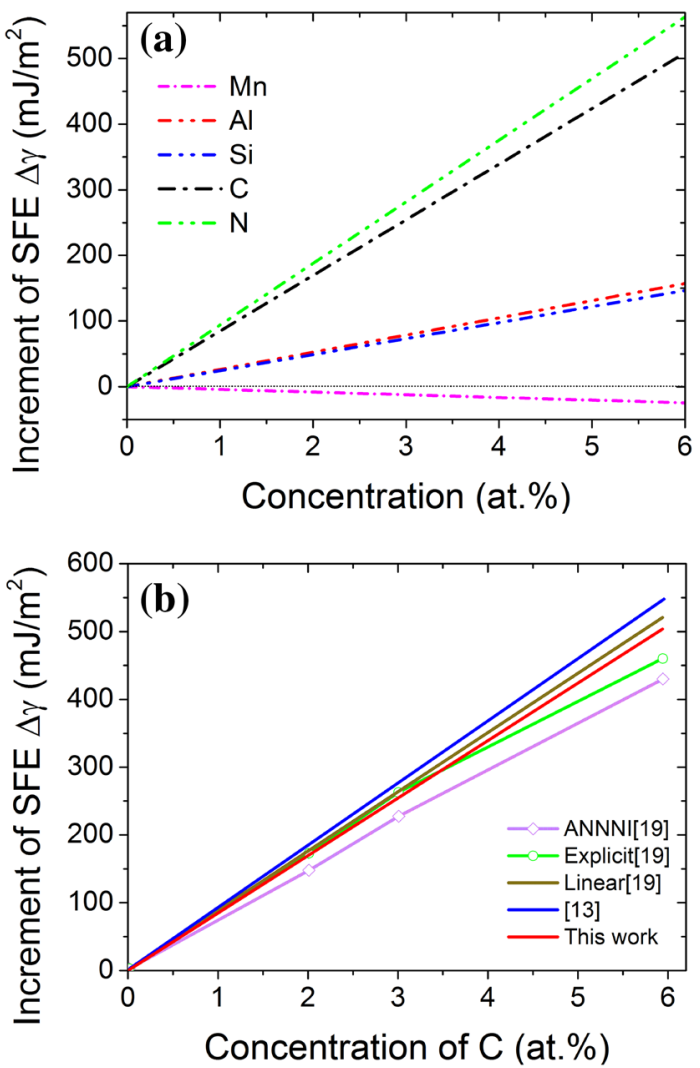

Fig. 3 a Increment of SFE $\Delta \gamma$ as function of the alloying atoms' concentration, where the black dot line refers to $\Delta \gamma=0$. b Dependence of the SFE as a function of the $\mathrm{C}$ concentration compared with previous experimental and DFT results

Table 1 Increment of SFE $\left(\mathrm{mJ} / \mathrm{m}^{2}\right) \Delta \gamma$ caused by 1 at.\% alloying atoms

\begin{tabular}{llllll}
\hline & $\mathrm{Mn}$ & $\mathrm{Al}$ & $\mathrm{Si}$ & $\mathrm{C}$ & $\mathrm{N}$ \\
\hline$\Delta \gamma$ & -4.1 & 26.2 & 24.4 & 84.8 & 93.9 \\
& $-3.0[43]$ & $9.0[8], 11.3[5]$ & & $>67.0[19]$ & $73.0[17]$ \\
\hline
\end{tabular}

exhibits the lowest energy among other positions, whereas interstitial atoms $\mathrm{C}$ and $\mathrm{N}$ prefer to occupy position 1 and form a $180^{\circ} \mathrm{Mn}-\mathrm{C} / \mathrm{N}-\mathrm{Mn}$ dimer (Fig. 4d, site 1). The binding energies between $2 \mathrm{Mn}$ and other atoms (i.e., $\mathrm{Al}$, $\mathrm{Si}, \mathrm{C}$ and $\mathrm{N}$ atoms) at their most favorable positions mentioned earlier were $-59.8,-42.1,-59.3$ and $-189.2 \mathrm{meV}$, respectively. These findings indicate that the $\mathrm{Mn}_{2}-X(X=\mathrm{Al}, \mathrm{Si}, \mathrm{C}$ and $\mathrm{N})$ trimers are very easily combined because of the strong attractive interaction between them.

Given the short-range interaction between SFs and alloy atoms, we also placed the $\mathrm{Mn}_{2}-X$ trimer close to the SFs in the large supercells (14-(111) layer and 36 atoms per layer). $E_{\text {int }}$ between $\mathrm{SFs}$ and $\mathrm{Mn}_{2}-\mathrm{Al}, \mathrm{Mn}_{2}-\mathrm{Si}$ and $\mathrm{Mn}_{2}-\mathrm{C}$ 
(a)

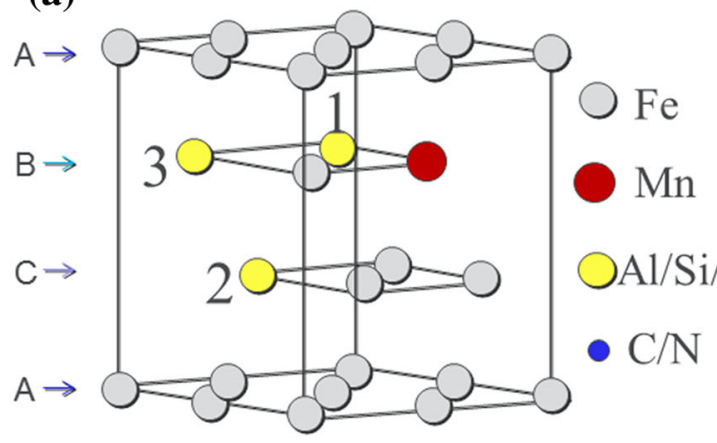

(c)

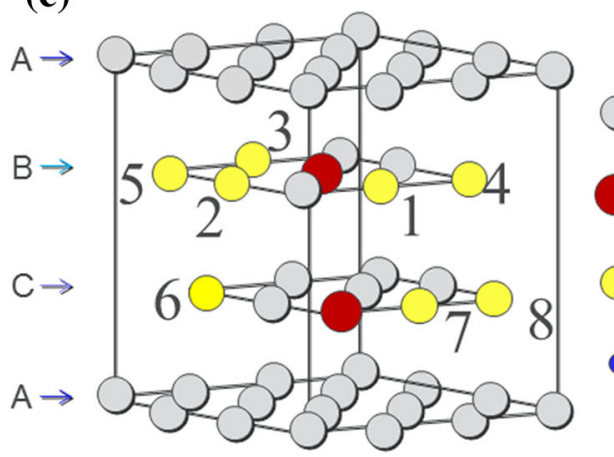

(b)

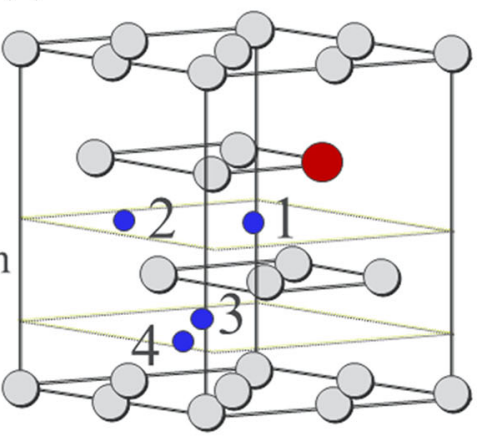

(d)

$\mathrm{Fe}$

$\mathrm{Mn}$

$\mathrm{Al} / \mathrm{Si}$

$\mathrm{C} / \mathrm{N}$

Fig. 4 Occupation sites for different alloying atoms in Fe alloy: a Mn- $X(X=\mathrm{Al} / \mathrm{Si} / \mathrm{Mn}), \mathbf{b} \mathrm{Mn}-X(X=\mathrm{C} / \mathrm{N}), \mathbf{c ~ M n}{ }_{2}-X(X=\mathrm{Al} / \mathrm{Si}), \mathbf{d ~ M n}{ }_{2}-$ $X(X=\mathrm{C} / \mathrm{N})$. For better visualization, 1/8 supercell is illustrated

Table 2 Relative total energies (meV) for alloying atoms of $\mathrm{Mn}-$ $X$ dimers $(X=\mathrm{Al}, \mathrm{Si}, \mathrm{C}$, and $\mathrm{N})$ in fcc $\mathrm{Fe}$

\begin{tabular}{lrrrr}
\hline Mn-X\sites & \multicolumn{1}{l}{1} & \multicolumn{1}{l}{3} & \multicolumn{1}{l}{4} \\
\hline $\mathrm{Mn}-\mathrm{Mn}$ & 13.5 & 0.0 & 2.3 & \\
$\mathrm{Mn}-\mathrm{Al}$ & 44.1 & 0.0 & 15.6 & \\
$\mathrm{Mn}-\mathrm{Si}$ & 18.2 & 0.0 & 4.0 & \\
$\mathrm{Mn}-\mathrm{C}$ & 0.0 & 16.7 & 4.4 & 7.5 \\
$\mathrm{Mn}-\mathrm{N}$ & 0.0 & 71.2 & 57.9 & 59.9 \\
\hline
\end{tabular}

Zero energy corresponding to the favorite configuration with the lowest energy. Alloying atom sites 1-4 are shown in Fig. $4 a, b$

trimers was $89.3,110.1$ and $43.4 \mathrm{meV}$, respectively, greater than those of the single $X$ atoms. Meanwhile, the $E_{\text {int }}$ between $\mathrm{SFs}$ and $\mathrm{Mn}_{2}-\mathrm{N}$ was slightly smaller $(\sim 10.0 \mathrm{meV})$ than that of the single $\mathrm{N}$ atom, which is consistent with the view that the addition of substitutional atom Mn exerts no significant effect on the SFE of Fe-Mn$\mathrm{N}$ steel, as predicted by Kibey et al. [17]. The $\Delta \gamma$ caused by the trimer with a concentration of 1 at.\% is denoted by a blue triangle in Fig. 5. The results indicate that in addition to $\mathrm{Mn}_{2}-\mathrm{N}$, the $E_{\text {int }}$ between SFs and other trimers was enhanced, and the SFEs increased significantly. In summary, as long as the $\mathrm{Mn}_{2}-X(X=\mathrm{Al}, \mathrm{Si}$ and $\mathrm{C})$ trimers

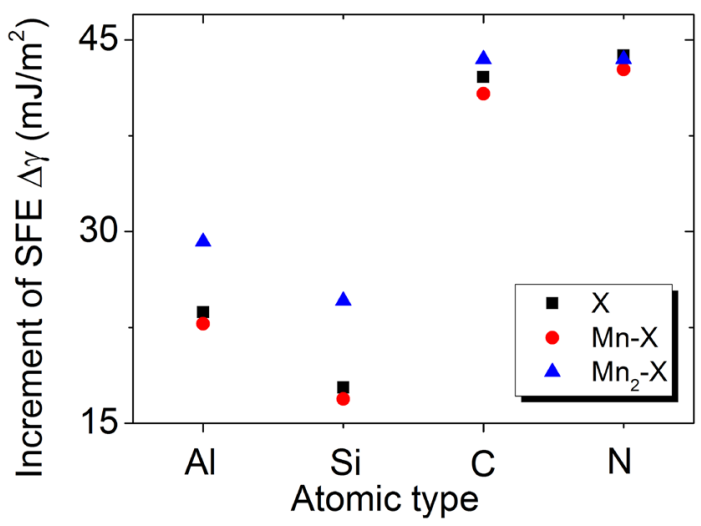

Fig. 5 Increment of SFE caused by 1 at.\% different types of alloying atoms located nearby the layer SF, where black square, red circle and blue triangle indicate single atom, $\mathrm{Mn}-X$ dimer and $\mathrm{Mn}_{2}-X$ trimer, respectively

form in high-concentration $\mathrm{Mn}$ steel, the SFE increases significantly.

In general, the synergistic effect of alloying atoms reflects a significant occurrence in multicomponent alloys. The influence of alloying atoms on SFE is not the algebraic sum of the individual effects of various alloying atoms. Instead, atoms interact, forming different types of atomic configurations that, in combination, influence the SFE. 
Table 3 Relative total energies $(\mathrm{meV})$ for alloying atoms of $\mathrm{Mn}_{2}-X$ trimers $(X=\mathrm{Al}, \mathrm{Si}, \mathrm{C}$, and $\mathrm{N})$ in fcc $\mathrm{Fe}$

\begin{tabular}{|c|c|c|c|c|c|c|c|c|}
\hline $\mathrm{Mn}_{2}-X \backslash$ sites & 1 & 2 & 3 & 4 & 5 & 6 & 7 & 8 \\
\hline $\mathrm{Mn}_{2}-\mathrm{Al}$ & 130.8 & 90.7 & 92.1 & 43.9 & 45.3 & 0.0 & 47.1 & 30.1 \\
\hline $\mathrm{Mn}_{2}-\mathrm{Si}$ & 89.1 & 63.9 & 67.9 & 32.3 & 31.7 & 0.0 & 37.3 & 18.2 \\
\hline $\mathrm{Mn}_{2}-\mathrm{C}$ & 0.0 & 16.2 & 15.3 & 8.2 & 33.1 & 3.2 & 17.8 & \\
\hline $\mathrm{Mn}_{2}-\mathrm{N}$ & 0.0 & 80.1 & 136.4 & 123.1 & 160.3 & 73.1 & 144.1 & \\
\hline
\end{tabular}

Zero energy corresponding to the configuration with the lowest energy. Alloying atom sites 1-8 are shown in Fig. 4c, d

\section{Conclusions}

On the basis of the DFT calculations, we investigated the influence of single atoms ( $\mathrm{Mn}, \mathrm{Al}, \mathrm{Si}, \mathrm{C}$ and $\mathrm{N}), \mathrm{Mn}-$ $X$ dimers and $\mathrm{Mn}_{2}-X$ trimers $(X=\mathrm{Al}, \mathrm{Si}, \mathrm{C}$ and $\mathrm{N})$ on the SFE of fcc Fe. The preferable distribution of $\mathrm{Mn}-X$ dimer and $\mathrm{Mn}_{2}-X$ trimer in the fcc Fe matrix was analyzed. The interaction of SFs between single atoms, $\mathrm{Mn}-X$ dimer and $\mathrm{Mn}_{2}-X$ trimer was then compared under the conditions of relatively low concentration $(<10 \mathrm{wt} \%)$. Finally, we reached the following conclusions:

1. The addition of Mn decreases the SFE, whereas Al, Si, $\mathrm{C}$ and $\mathrm{N}$ significantly increase the SFE.

2. When Mn combined with other alloying atoms to form Mn- $X$ dimers ( $X=\mathrm{Al}, \mathrm{Si}, \mathrm{C}$ and $\mathrm{N})$, their influence on the SFE is almost similar to those of the corresponding single $X$ atoms.

3. The interaction between $\mathrm{Mn}_{2}-X$ trimers $(X=\mathrm{Al}, \mathrm{Si}$ and $\mathrm{C}$ ) and SF is stronger than those of the corresponding single $X$ atoms, causing a significant increase in the SFE of fcc Fe. Meanwhile, the effect of $\mathrm{Mn}_{2}-\mathrm{N}$ on the SFE of fcc Fe is almost equal to that of the single $\mathrm{N}$ atom.

Acknowledgements This work is supported by the National Key Research and Development Program of China (No. 2016YFB0300801), the National Natural Science Foundation of China (Nos. 11427806, 51471067, 51371081, 51671082 and 51601060), the Specialized Research Fund for the Doctoral Program of Higher Education of China (No. 20120161110036), the Hunan Provincial Natural Science Foundation of China (No. 14JJ4052). The calculations were performed using the National Supercomputing Center in Changsha, China.

\section{References}

[1] C.M. Sonsino, Materwiss. Werksttech. 38, 9 (2007)

[2] D. Canadinc, H. Sehitoglu, H.J. Maier, Y.I. Chumlyakov, Acta Mater. 53, 1831 (2005)

[3] K.T. Park, K.G. Jin, S.H. Han, S.W. Hwang, K. Choi, C.S. Lee, Mater. Sci. Eng. A 527, 3651 (2010)

[4] X. Liang, J.R. McDermidb, O. Bouaziz, X. Wang, J.D. Emburya, H.S. Zurob, Acta Mater. 57, 3978 (2009)
[5] J. Kim, S.J. Lee, B.C. De Cooman, Scripta Mater. 65, 363 (2011)

[6] H. Gholizadeh, C. Draxl, P. Puschnig, Acta Mater. 61, 341 (2013)

[7] X. Peng, D. Zhu, Z. Hu, W. Yi, H. Liu, M. Wang, Mater. Des. 45, 518 (2013)

[8] N.I. Medvedeva, M.S. Park, D.C. Van Aken, J.E. Medvedeva, J. Alloys Compd. 582, 475 (2014)

[9] K. Jeong, J.E. Jin, Y.S. Jung, S. Kang, Y.K. Lee, Acta Mater. 61, 3399 (2013)

[10] A. Dumay, J.P. Chateau, S. Allain, S. Migot, O. Bouaziz, Mater. Sci. Eng. A 483, 184 (2008)

[11] A.V. Ruban, S. Khmelevskyi, P. Mohn, B. Johansson, Phys. Rev. B 75, 054402 (2007)

[12] Y.K. Lee, C.S. Choi, Metall. Mater. Trans. A 31, 355 (2000)

[13] R.E. Schramm, R.P. Reed, Metall. Mater. Trans. A 6, 1345 (1975)

[14] T. Yonezawa, K. Suzuki, S. Ooki, A. Hashimoto, Metall. Mater. Trans. A 44, 5884 (2013)

[15] P.J.H. Denteneer, W. Haeringen, J. Phys. C Solid State Phys. 20, 883 (1987)

[16] I.A. Yakubtsov, A. Ariapour, D.D. Perovic, Acta Mater. 47, 1271 (1999)

[17] S. Kibey, J.B. Liu, M.J. Curtis, D.D. Johnson, H. Sehitoglu, Acta Mater. 54, 2991 (2006)

[18] A. Dick, T. Hickel, J. Neugebauer, Steel Res. Int. 80, 603 (2009)

[19] A. Abbasi, A. Dick, T. Hickel, J. Neugebauer, Acta Mater. 59, 3041 (2011)

[20] W. Li, S. Lu, Q.M. Hu, B. Johansson, S.K. Kwon, M. Grehk, J.Y. Johnsson, L. Vitos, Phil. Mag. 96, 524 (2016)

[21] N.I. Medvedeva, D. Van Aken, J.E. Medvedeva, J. Phys. Condens. Matter 22, 316002 (2010)

[22] O. Grässel, L. Krüger, G. Frommeyer, L.W. Meyer, Int. J. Plast. 16, 1391 (2000)

[23] O. Bouaziz, S. Allain, C.P. Scott, P. Cugy, D. Barbier, Curr. Opin. Solid State Mater. Sci. 15, 141 (2011)

[24] L. Bracke, K. Verbeken, L. Kestens, J. Penning, Acta Mater. 57, 1512 (2009)

[25] Y. Lü, D.A. Molodov, G. Gottstein, Acta Mater. 59, 3229 (2011)

[26] D. Geissler, J. Freudenberger, A. Kauffmann, M. Krautz, H. Klauss, A. Voss, J. Eickemeyer, L. Schultz, Acta Mater. 59, 7711 (2011)

[27] Y.N. Dastur, W.C. Leslie, Metall. Trans. A 12, 749 (1981)

[28] K. Renard, H. Idrissi, D. Schryvers, P.J. Jacques, Scripta Mater. 66, 966 (2012)

[29] D.R. Steinmetz, T. Jäpel, B. Wietbrock, P. Eisenlohr, I. Gutierrez-Urrutia, A. Saeed-Akbari, T. Hickel, F. Roters, D. Raabe, Acta Mater. 61, 494 (2013)

[30] S.J. Lee, J. Kim, S.N. Kane, B.C.D. Cooman, Acta Mater. 59, 6809 (2011)

[31] T. Gebhardt, D. Music, D. Kossmann, M. Ekholm, I.A. Abrikosov, L. Vitos, J.M. Schneider, Acta Mater. 59, 3145 (2011) 
[32] S. Shang, Y. Wang, Y. Du, M.A. Tschopp, Z.K. Liu, Comput. Mater. Sci. 91, 50 (2014)

[33] Y.N. Petrov, Scripta Metall. Mater. 29, 1471 (1993)

[34] P.J. Brofman, G.S. Ansell, Metall. Trans. A 9, 879 (1978)

[35] K.R. Limmer, J.E. Medvedeva, D.C.V. Aken, N.I. Medvedeva, Comp. Mater. Sci. 99, 253 (2015)

[36] D. Canadinc, I. Karaman, H. Sehitoglu, Y.I. Chumlyakov, H.J. Maier, Metall. Mater. Trans. A 34, 1821 (2003)

[37] R.E. Stoltz, J.B.V. Sande, Metall. Mater. Trans. A 11, 1033 (1980)

[38] V. Gavriljuk, Y. Petrov, B. Shanina, Scripta Mater. 55, 537 (2006)
[39] V.G. Gavriljuk, H. Berns, C. Escher, N.I. Glavatskaya, A. Sozinov, Y.N. Petrov, Mater. Sci. Eng. A 271, 14 (1999)

[40] T.W. Fan, L.T. Wei, B.Y. Tang, L.M. Peng, D.W. Jiang, Phil. Mag. 94, 1578 (2014)

[41] L.H. Liu, J.H. Chen, T.W. Fan, Z.R. Liu, Y. Zhang, D.W. Yuan, Comp. Mater. Sci. 108, 136 (2015)

[42] G. Kresse, J. Furthmüller, Phys. Rev. B 54, 11169 (1996)

[43] P.E. Blöchl, Phys. Rev. B 50, 17953 (1994)

[44] K.B. John, P. Perdew, M. Ernzerhof, Phys. Rev. Lett. 77, 3865 (1996) 